\title{
Neuronal plasticity of trigeminal ganglia in mice following nerve injury
}

\author{
Randi Lynds ${ }^{1,2, *}$ \\ Chuang Lyu ${ }^{3, *}$ \\ Gong-Wei Lyu ${ }^{4}$ \\ Xie-Qi Shi ${ }^{1,2}$ \\ Annika Rosén ${ }^{5,6}$ \\ Kamal Mustafa ${ }^{6}$ \\ Tie-Jun Sten $\mathrm{Shi}^{7}$
}

'Department of Dental Medicine, Karolinska Institutet, Huddinge, Sweden; ${ }^{2}$ Division of Oral and Maxillofacial Radiology, Department of Clinical Dentistry, Faculty of Medicine and Dentistry, University of Bergen, Bergen, Norway; ${ }^{3}$ State Key Laboratory of Veterinary Biotechnology, Harbin Veterinary Research Institute of Chinese Academy of Agricultural Sciences, ${ }^{4}$ Department of Neurology, The First Hospital of Harbin Medical University, Harbin, People's Republic of China; ${ }^{5}$ Division for Oral and Maxillofacial Surgery, ${ }^{6}$ Tissue Engineering Group, Department of Clinical Dentistry, Faculty of Medicine and Dentistry, ${ }^{7}$ Department of Biomedicine, University of Bergen, Bergen, Norway

*These authors contributed equally to this work
This article was published in the following Dove Press journal:

Journal of Pain Research

9 February 2017

Number of times this article has been viewed

Background: Nerve injury may induce neuropathic pain. In studying the mechanisms of orofacial neuropathic pain, attention has been paid to the plastic changes that occur in the trigeminal ganglia (TGs) and nucleus in response to an injury of the trigeminal nerve branches. Previous studies have explored the impact of sciatic nerve injury on dorsal root ganglia (DRGs) and it has shown dramatic changes in the expression of multiple biomarkers. In large, the changes in biomarker expression in TGs after trigeminal nerve injury are similar to that in DRGs after sciatic nerve injury. However, important differences exist. Therefore, there is a need to study the plasticity of biomarkers in TGs after nerve injury in the context of the development of neuropathic pain-like behaviors.

Aim: The aim of this study was to investigate the plasticity of biomarkers associated with chronic persistent pain in TGs after trigeminal nerve injury.

Materials and methods: To mimic the chronic nature of the disorder, we used an intraoral procedure to access the infraorbital nerve (ION) and induced a nerve injury in mice. Immunohistochemistry and quantification were used for revealing the expression level of each biomarker in TGs after nerve injury.

Results: Two weeks after partial ION injury, immunohistochemistry results showed strongly upregulated expressions of activating transcription factor 3 and neuropeptide Y (NPY) in the ipsilateral TGs. Microglial cells were also activated after nerve injury. In regard to positive neuronal profile counting, however, no significant difference in expression was observed in galanin, substance $\mathrm{P}$, calcitonin gene-related peptide, neuronal nitric oxide synthase, phosphorylated AKT, or P2X3 in ipsilateral TGs when compared to contralateral TGs.

Conclusion: In this study, the expression and regulation of biomarkers in TGs have been observed in response to trigeminal nerve injury. Our results suggest that NPY and Iba1 might play crucial roles in the pathogenesis of orofacial neuropathic pain following this type of injury. Further investigations on the relevance of these changes may help to target suitable treatment possibilities for trigeminal neuralgia.

Keywords: infraorbital nerve, orofacial pain, sensory neurons, neuropeptides, animal model

\section{Introduction}

Trigeminal neuralgia is regarded as being one of the most painful diseases known. ${ }^{1}$ Pain resulting from this disease impairs patients' mood, quality of life, daily life activities, and work performance. ${ }^{2}$ Known factors that can cause trigeminal neuralgia are injury, inflammation, and vascular compression of the trigeminal nerve. ${ }^{3,4}$ However, the mechanisms of trigeminal neuralgia are still poorly understood.
Correspondence: Tie-Jun Sten Shi Department of Clinical Dentistry, University of Bergen, Årstadveien 19, PO Box 7804, 5020 Bergen, Norway Tel +4745392855

Email tjstenshi@gmail.com 
Sensory neuron plasticity after peripheral injury is considered important for understanding the development of chronic persistent pain. ${ }^{5}$ Studies have revealed that the impact that sciatic nerve injury has on dorsal root ganglia (DRGs) causes dramatic changes in the expression of certain peptides, more specifically excitatory peptides such as substance $\mathrm{P}$ (SP) and calcitonin gene-related peptide (CGRP), as well as inhibitory and excitatory neuropeptides such as galanin (GAL) and neuropeptide Y (NPY) ${ }^{6,7}$ Neuronal nitric oxide synthase (nNOS) and P2X3 are also known to play a role in nociception. ${ }^{89}$ Phosphorylated AKT (pAKT) is believed to have neuroprotective effects and can be regulated in sensory ganglia after injury. ${ }^{5,10,11}$ All of these changes may have implications in the generation and modulation of neuropathic pain. ${ }^{12}$ To our knowledge, only a limited number of studies have been conducted to examine neuronal plasticity of the trigeminal ganglion (TG) following trigeminal nerve injury. These studies show that the changes in neuropeptide expression of TGs after trigeminal nerve injury are similar to DRGs after sciatic nerve injury. ${ }^{13,14}$ However, important differences exist. For example, GAL is markedly upregulated in DRGs after sciatic nerve injury, ${ }^{15}$ whereas GAL expression in TGs has been inconclusive, with results showing an increase, no change, or even decrease in expression after facial nerve injury. ${ }^{13,16}$ Interestingly, systematic studies have not been conducted on the expression of neuropeptides in TGs after nerve injury in the context of the development of neuropathic pain-like behaviors, as in the case of sciatic nerve injury. ${ }^{17}$

Recently, several animal models have been developed to examine trigeminal nerve injury, inflammation, and trigeminal nerve root compression. ${ }^{18-21}$ Among these models, the infraorbital nerve (ION) constriction model of trigeminal neuralgia has been performed in both rats and mice. ${ }^{22-24}$ Interestingly, animal models of trigeminal neuralgia obtained by a chronic constriction injury of ION are shown to share many characteristics with clinical disorders in humans. ${ }^{25,26}$

Because pain-related biomarkers give accurate signals, observing and understanding their changes may help us find potential targets for treating painful diseases. In this study, we investigated the expression of several biomarkers in TGs following trigeminal nerve injury. Expression and regulation of activating transcription factor 3 (ATF3), NPY, Iba1, GAL, CGRP, SP, nNOS, pAKT, and P2X3 were examined in a modified mouse model of trigeminal neuralgia.

\section{Materials and methods}

\section{Animals}

Adult male C57BL/6J Bommince mice (A/S Bomholtgaard, Ry, Denmark) weighing 28-30 g were used in this study.
All animals were kept under standard conditions on a 12-h day/night cycle with free access to food and water. The experiments were carried out according to the International Association for the Study of Pain Guidelines for the Use of Animals in Research and were approved by Karolinska Institutet ethics committee (registration number: N48/13).

\section{Operation}

Mice were anesthetized with isoflurane, received a transection to the left ION, and the contralateral side (right side) was used as a control. The surgery was performed intraorally, which allowed the hair on the snout and the vibrissae to be kept intact. A transection of $\sim 0.5 \mathrm{~cm}$ was made unilaterally along the left gingivobuccal margin. The transection began at $\sim 0.1 \mathrm{~cm}$ proximal to the first molar. The modification of surgery is based on two previously published studies. ${ }^{27,28}$ The mice were sacrificed 2 weeks after surgery.

\section{Immunohistochemistry}

All operated animals were deeply anesthetized with sodium pentobarbital $(50 \mathrm{mg} / \mathrm{kg}$, i.p.) and transcardially perfused with $20 \mathrm{~mL}$ of warm saline $\left(0.9 \% ; 37^{\circ} \mathrm{C}\right)$, followed by $20 \mathrm{~mL}$ of a warm mixture of paraformaldehyde $\left(4 \% ; 37^{\circ} \mathrm{C}\right)$ with $0.4 \%$ picric acid in $0.16 \mathrm{M}$ phosphate buffer ( $\mathrm{pH} 7.2)$ and then by $50 \mathrm{~mL}$ of the same, but ice-cold fixative. Both the ipsilateral and contralateral TGs were dissected out and postfixed in the same fixative for $90 \mathrm{~min}$ at $4^{\circ} \mathrm{C}$ and subsequently stored in $10 \%$ sucrose in phosphate-buffered saline (PBS; pH 7.4) containing $0.01 \%$ sodium azide (Sigma-Aldrich Co., St Louis, MO, USA) and $0.02 \%$ bacitracin (Sigma-Aldrich Co.) at $4{ }^{\circ} \mathrm{C}$ for 2 days. Tissues were embedded with optimum cutting temperature compound (Tissue-Tek; Miles Laboratories, Elkhart, IN, USA), frozen and cut in a cryostat (Microm, Heidelberg, Germany) at $14 \mu \mathrm{m}$ thickness, and then mounted onto chrome-alum-gelatin-coated slides. Thaw-mounted sections were dried at room temperature (RT) for $30 \mathrm{~min}$ and rinsed with PBS for $15 \mathrm{~min}$. Sections were incubated for $24 \mathrm{~h}$ at $4{ }^{\circ} \mathrm{C}$ in a humid chamber with rabbit anti-ATF3 (1:4,000; D1610, Santa Cruz Biotechnology, Dallas, TX, USA), NPY $(1: 8,000),{ }^{29}$ rabbit anti-GAL $(1: 8,000),{ }^{30}$ rabbit anti-SP $(1: 4,000),{ }^{31}$ rabbit anti-CGRP $(1: 10,000),{ }^{32}$ sheep anti-nNOS $(1: 4,000),{ }^{32}$ rabbit anti-pAKT $(1: 4,000 ;$ G7441, Promega Corporation, Madison, WI, USA), and rabbit anti-P2X3 $(1: 4,000)^{33}$ antisera diluted in PBS containing $0.2 \%(\mathrm{w} / \mathrm{v})$ bovine serum albumin and $0.03 \%$ Triton X-100. Immunoreactivity was visualized using the tyramide signal amplification system (TSA Plus; NEN Life Science Products, Boston, MA, USA). Briefly, the slides were rinsed with TrisHCL/NaCL/Tween-20 (TNT) buffer (0.1 M Tris-HCl, pH 7.5; 
$0.15 \mathrm{M} \mathrm{NaCl} ; 0.05 \%$ Tween-20) for $15 \mathrm{~min}$ at $\mathrm{RT}$, blocked with Tris-HCL/NaCL/DuPont blocking reagent (TNB) buffer (0.1 M Tris-HCl; pH 7.5; $0.15 \mathrm{M} \mathrm{NaCl} ; 0.5 \%$ DuPont blocking reagent) for $30 \mathrm{~min}$ at RT followed by a 30-min incubation with horseradish peroxidase-labeled swine antirabbit and/or anti-sheep antibody (1:200; Dako Denmark A/S, Glostrup, Denmark) diluted in TNB buffer. After a quick wash (15 min) in TNT buffer, all sections were exposed to biotinyl tyramide-fluorescein (1:100) diluted in amplification diluent for $10 \mathrm{~min}$, and finally washed in TNT buffer for $30 \mathrm{~min}$ (all steps performed at RT). Sections to be used for profile counts (with nucleus) were counterstained for $8-10 \mathrm{~min}$ in $0.001 \%$ $(\mathrm{w} / \mathrm{v})$ propidium iodide (PI; Sigma-Aldrich Co.) in PBS, rinsed twice for $5 \mathrm{~min}$ in PBS, and mounted with glycerol/ PBS (9:1) containing 2.5\% DABCO (Sigma-Aldrich Co.).

\section{Image analysis and quantification}

Specimens were analyzed on a Bio-Rad Radiance Plus confocal scanning microscope (Bio-Rad, Hemel Hempstead, UK) installed on a $710 \mathrm{LSM}$ laser-scanning microscope equipped with $\times 10(0.5$ numerical aperture $[\mathrm{NA}]), \times 20(0.75 \mathrm{NA})$, and $\times 60$ (1.40 NA) oil objectives. Fluorescein labeling was excited using the $488 \mathrm{~nm}$ line of the argon ion laser and detected after passing a HQ 530/60 (Bio-Rad Laboratories Inc.) emission filter. All the slides were scanned in a series of $1 \mu \mathrm{m}$ thick optical sections.

To determine the percentage of immunoreactive (IR) neuronal profiles (NPs), the counting was performed on $14-\mu \mathrm{m}$-thick sections, and every fifth section was selected. The total number of immunopositive NPs was divided by the total number of PI-stained NPs in the TG sections, and the percentage of positive NPs was calculated. Four to eight sections of each TG from five animals in each group (i.e., ipsilateral and contralateral groups) were included in the analysis, and 1,200-1,800 NPs were counted in each ganglion.

\section{Statistical analysis}

Unpaired Student's $t$-test was used for the comparison of difference between ipsilateral and contralateral expression of each biomarker. $p<0.05$ was taken as the criterion for statistical significance $(* p<0.05, * * p<0.01$, and $* * * p<0.001)$.

\section{Results}

\section{ATF3 expression in TGs after ION injury}

ATF3-IR NPs were almost undetectable in the contralateral TGs 2 weeks after partial ION injury. However, a strong upregulation of ATF3-IR NPs was seen in the ipsilateral TGs, as shown in Figure 1A, B versus $\mathrm{C}$ and Figure $2(0.9 \pm 0.2 \%$ vs. $30.1 \pm 5.8 \% ; p<0.001)$, mainly in the maxillary infraorbital neurons (Figure 1A; red box).

\section{Expression of biomarkers in TGs after ION injury}

In the contralateral TGs, very few NPs were NPY positive $(1.8 \pm 0.9 \%)$, while a dramatic increased expression of NPYpositive NPs was seen in the ipsilateral TGs $(12.9 \pm 5.6 \%$; $p<0.01$; Figures $2-4 \mathrm{~A}$ and B). This increase is $\sim 10$-fold when compared to the control. Regarding GAL expression, more positive NPs were found in the ipsilateral TGs, but this increase in expression was not statistically significant $(11.5 \pm 5.8 \%$ vs. $13 \pm 4.8 \% ; p>0.05$; Figures 2 and 3 ). No significant difference was detected between the ipsilateral and contralateral TGs for
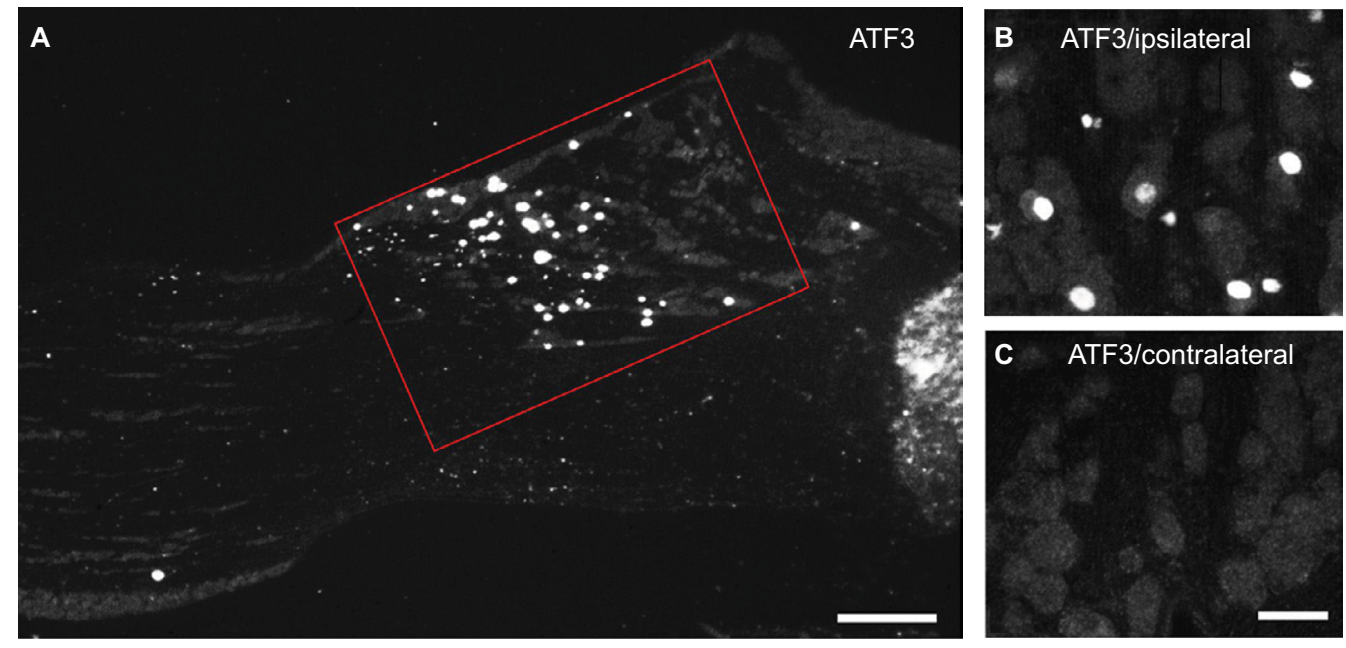

Figure I Expression of ATF3-LI in TGs 2 weeks after partial ION transection.

Notes: (A) ATF3-LI is mainly seen in the infraorbital neurons (red box) in ipsilateral TGs. (B and C) High magnification micrographs show the expression of ATF3-IR neurons in ipsilateral (B) and contralateral (C) TGs. Scale bars indicate $250 \mu \mathrm{m}(\mathbf{A})$ and $50 \mu \mathrm{m}(\mathbf{B}$ and $\mathbf{C})$.

Abbreviations: ATF3, activating transcription factor 3; ION, infraorbital nerve; IR, immunoreactive; LI, like immunoreactivity; TGs, trigeminal ganglia. 


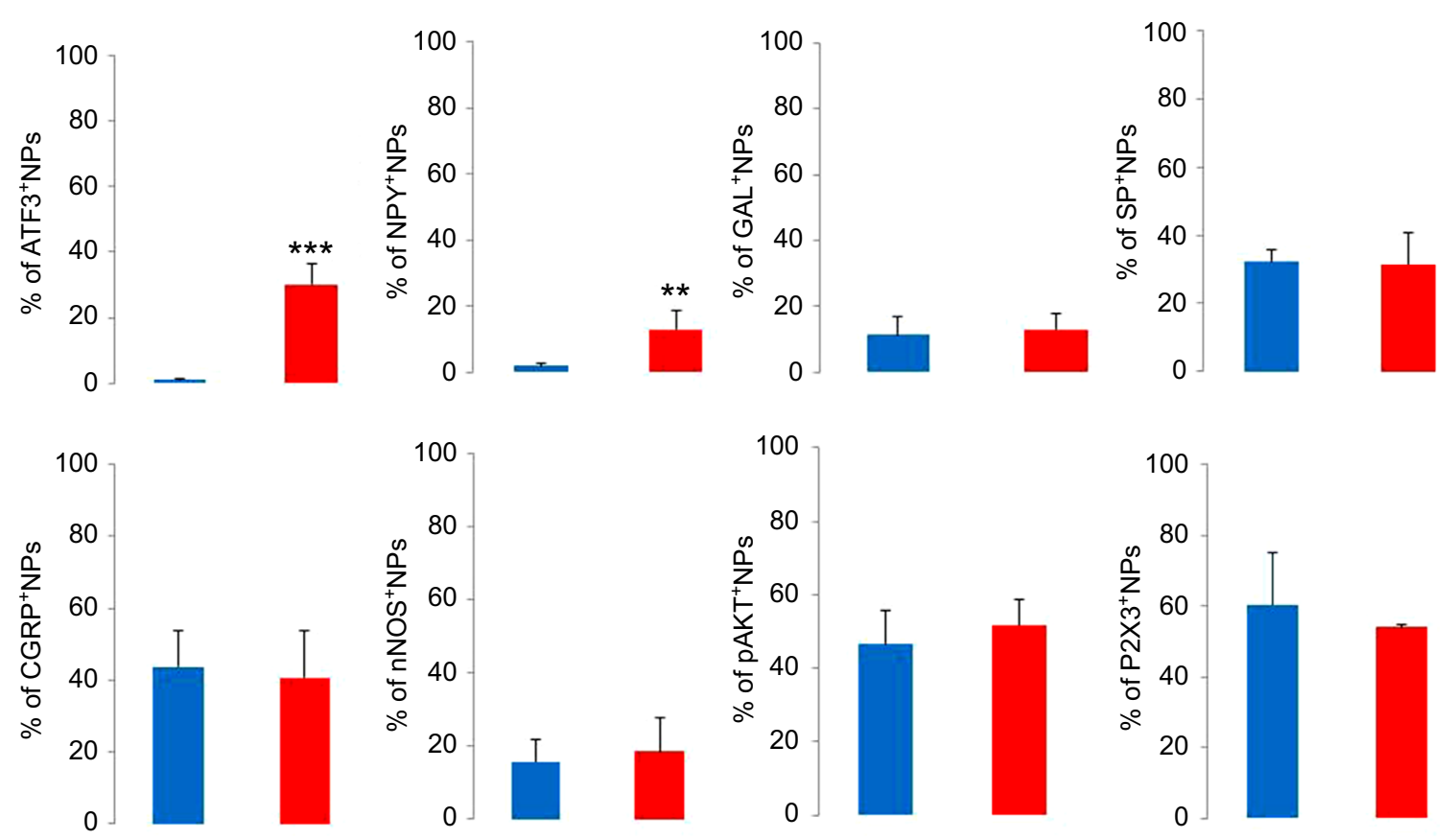

Figure 2 Percentage of positive NPs in contralateral and ipsilateral TGs 2 weeks after partial ION transection.

Note: The columns represent contralateral (blue) and ipsilateral (red) TGs, respectively ( $\mathrm{n}=5$ in each group, $\left.{ }^{* *} p<0.0 \mathrm{I}, *^{* *} p<0.00 \mathrm{I}\right)$.

Abbreviations: ATF3, activating transcription factor 3; CGRP, calcitonin gene-related peptide; GAL, galanin; ION, infraorbital nerve; nNOS, neuronal nitric oxide synthase; NPs, neuronal profiles; NPY, neuropeptide Y; PAKT, phosphorylated AKT; SP, substance P; TGs, trigeminal ganglia.

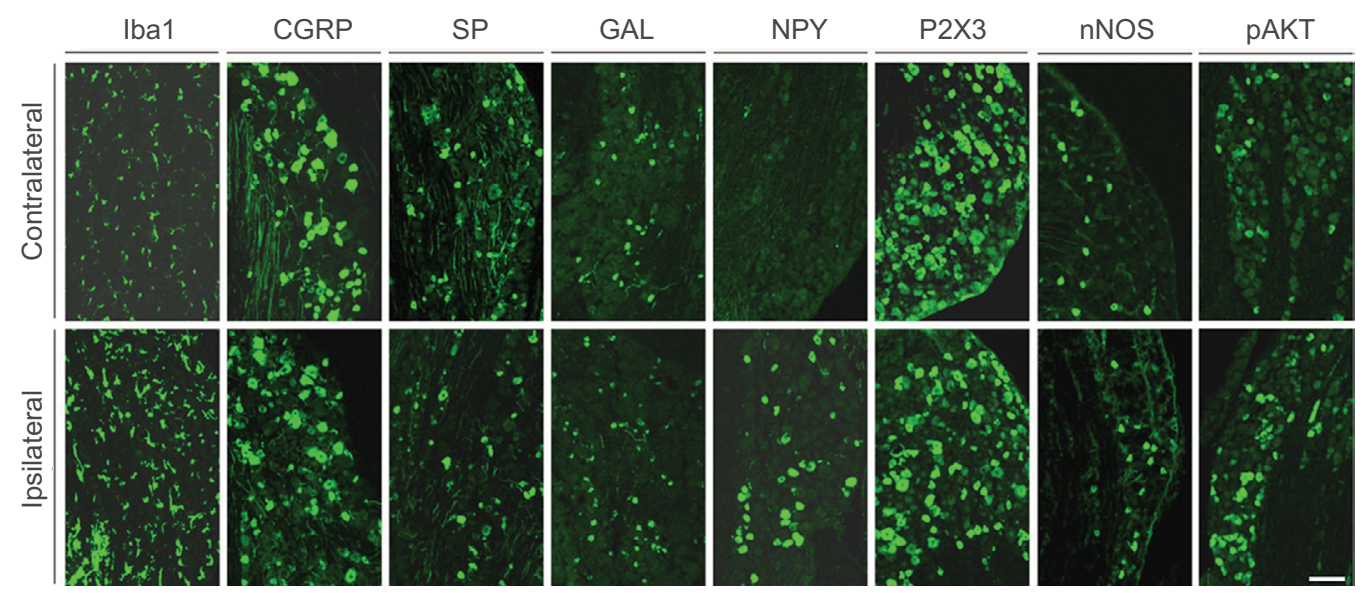

Figure 3 Immunofluorescent micrographs show the expression of biomarkers in contralateral (top panel) and ipsilateral (bottom panel) TGs 2 weeks after partial ION transection.

Notes: Sections were incubated with antisera of Ibal, CGRP, SP, GAL, NPY, P2X3, nNOS, and pAKT, respectively. Scale bar indicates I00 $\mu$ m.

Abbreviations: CGRP, calcitonin gene-related peptide; ION, infraorbital nerve; nNOS, neuronal nitric oxide synthase; NPY, neuropeptide Y; pAKT, phosphorylated AKT; SP, substance P; TGs, trigeminal ganglia.

CGRP $(43.7 \pm 9.9 \%$ vs. $40.9 \pm 13.0 \%$; Figures 2,3 , and $5 \mathrm{~A})$, SP (32.2 $\pm 3.7 \%$ vs. $31.6 \pm 9.1 \%$; Figures 2,3 , and $5 \mathrm{~B}), \mathrm{P} 2 \mathrm{X} 3$ $(60.4 \pm 15.8 \%$ vs. $54.0 \pm 1.3 \%$; Figures 2 and 3$)$, or nNOS $(15.9 \pm 6.0 \%$ vs. $18.6 \pm 9.3 \%$; Figures 2 and 3), respectively. pAKT-like immunoreactivity (pAKT-LI) was seen in many neurons in intact TGs (Figure 5C), especially small-sized ones. pAKT had a relatively high intensity in ipsilateral TGs but the percentage of positive-NPs remained the same 2 weeks after ION injury ( $46.6 \pm 9.2 \%$ vs. $51.5 \pm 7.1 \%$; Figures 2 and 3$)$.
Iba1, a marker for activated microglial cells, was activated in the ipsilateral TGs as compared to contralateral ones 2 weeks after partial ION injury (Figures 3 and 4C-F). The expression of Iba1-LI in the contralateral TGs presented a typical resting microglial morphology (Figures 3 and $4 \mathrm{C}$ and $\mathrm{E}$ ). By contrast, the enlarged and amoeboid morphological features of activated microglia cell bodies were seen in the ipsilateral TGs (Figures 3 and 4D and F), which are consistent with previous findings. ${ }^{34}$ 
A

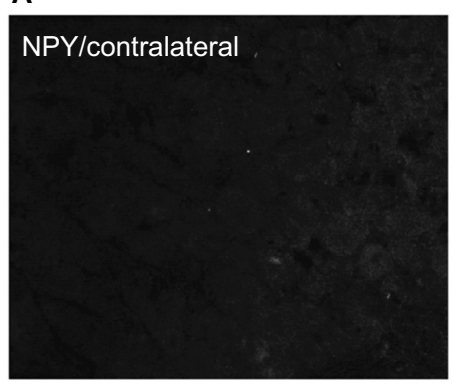

C

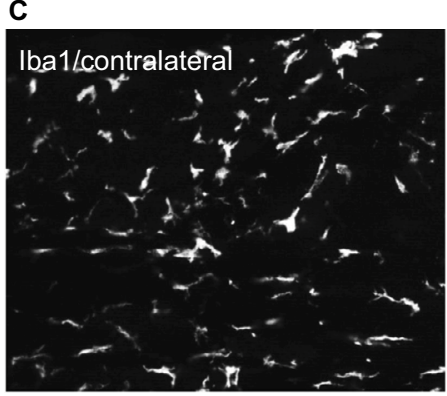

E

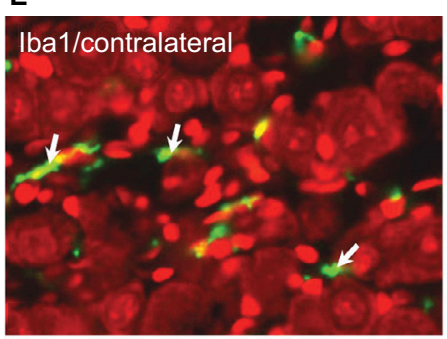

B

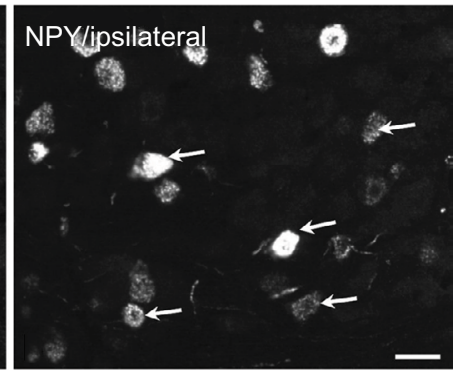

D

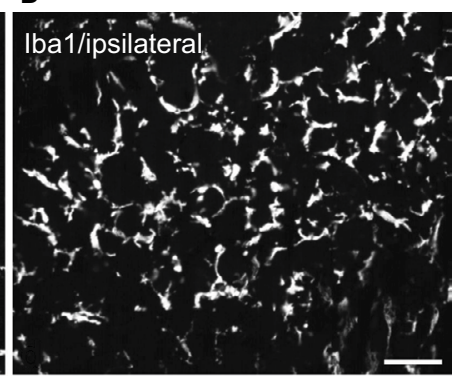

$\mathbf{F}$

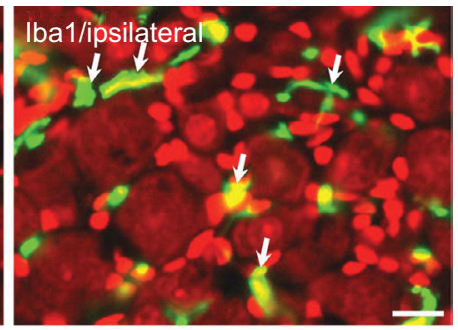

Figure 4 Expression of NPY and Ibal in ipsilateral and contralateral TGs 2 weeks after partial ION transection.

Notes: NPY-LI is upregulated in ipsilateral TG (B) compared with the contralateral one (A). Immunofluorescence micrographs show a hypertrophic morphology of Iba I-LI in ipsilateral ( $\mathbf{D}$ and $\mathbf{F})$ vs. contralateral TGs (C and $\mathbf{E})$, counterstaining with PI (red) (E and $\mathbf{F})$. Arrows indicate the NPY-positive neurons $(\mathbf{B})$ and lbal-positive microglial cells $(\mathbf{E}$ and $\mathbf{F})$, respectively. Scale bars indicate $50 \mu \mathrm{m}(\mathbf{A}$ and $\mathbf{B}), 30 \mu \mathrm{m}(\mathbf{C}$ and $\mathbf{D})$, and $25 \mu \mathrm{m}(\mathbf{E}$ and $\mathbf{F})$.

Abbreviations: ION, infraorbital nerve; LI, like immunoreactivity; NPY, neuropeptide Y; PI, propidium iodide; TGs, trigeminal ganglia.

A

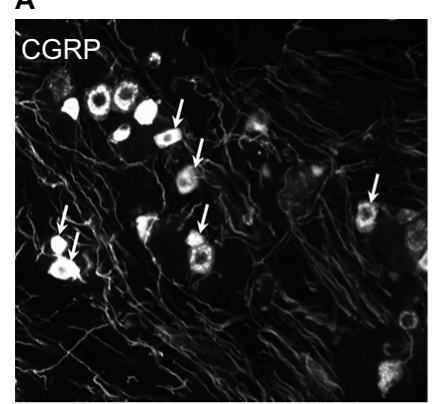

B

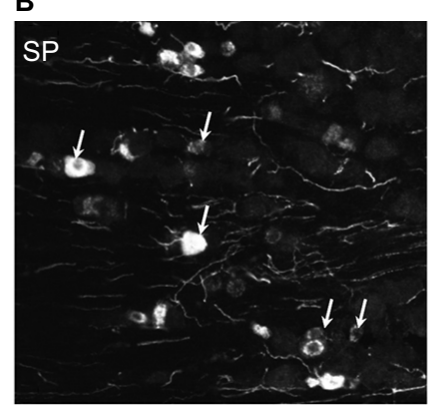

C

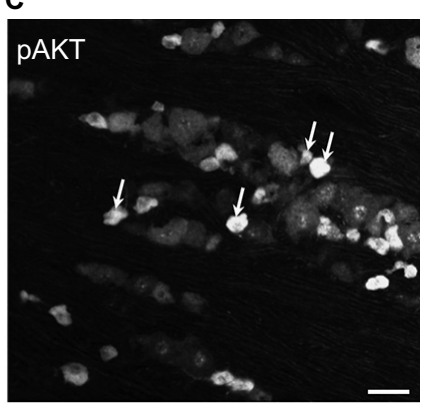

Figure 5 Immunofluorescent micrographs show the expression of biomarkers in contralateral TGs 2 weeks after partial ION transection.

Notes: CGRP-LI (A), SP-LI (B), and PAKT-LI (C) are present in the TG neurons. Arrows indicate positive neurons. Scale bar indicates $50 \mu \mathrm{m}$.

Abbreviations: CGRP, calcitonin gene-related peptide; ION, infraorbital nerve; LI, like immunoreactivity; SP, substance P; TGs, trigeminal ganglia; pAKT, phosphorylated AKT.

\section{Discussion}

In this study, we investigated the expression and regulation of several biomarkers in TGs 2 weeks after partial ION injury in mice. Following the ION transection and based on the NP counting method, dramatic changes of ATF3, Iba1, and NPY-LIs were observed but minor to no changes of SP, CGRP, nNOS, pAKT, or P2X3 were found in injured TGs as compared with contralateral uninjured controls. These findings suggest that distinct mechanisms of adaptation to nerve injury may exist in TGs when compared to spinal 
ganglia, and that NPY and activated glial cells may play a more important role in trigeminal neuralgia.

Several animal models have been developed for mimicking the injured condition of the human trigeminal nerve..$^{35,36}$ Regarding the model of ION injury, the surgery has mostly been performed on rats by incising the skin above the unilateral eye. ${ }^{37,38}$ It is known that many nerve fibers of the facial nerve are distributed around eyes, both in superficial and deep layers. Therefore, exposing the ION through the extraoral approach can inevitably cause damage to the facial nerve and other tissues. This extra tissue damage may disturb the results of behavioral studies and make it more difficult to determine the origin of pain. The model used in this study was modified from a previous report, i.e., the surgery was carried out intraorally, and the damage of other cranial nerves and tissues was greatly limited. ${ }^{27}$

ATF3 is often used as a marker of damaged neurons, as its upregulation indicates subtle damage to the neurons and/ or their axons. ${ }^{39,40}$ Here, we report that ATF3 is significantly upregulated in the ipsilateral TGs vs. the contralateral TGs 2 weeks after partial injury of ION. ATF3-LI was seen in the axotomized neurons, especially in the nucleus and sometimes cytoplasm. In addition, most maxillary infraorbital neurons were ATF3 positive in the ipsilateral TGs, indicating that the axons of these neurons projecting to ION were injured following partial ION transection. This result further demonstrates that the transection of ION can induce a specific nocuous stimulation on the corresponding territory innervated by ION afferents, triggering dramatic plasticity changes in neuronal receptive fields in the TGs, and thus further reflects that the partial ION injury model of trigeminal neuralgia in mouse used in this study has achieved an injured specificity. These results are in line with previous findings that an increase of ATF3-LI was seen in the ipsilateral TG neurons, in the ION-innervated region, after partial ION ligation. ${ }^{41}$

Recent studies suggest that microglial cells are vital players in the immune response to injury and are largely implicated in chronic pain conditions. In most cases, activation of microglial cells accompanies an increased expression of a biomarker, i.e., Iba1. ${ }^{42,43}$ Moreover, microglial activation in the spinal cord contributes to pain hypersensitivity, and it has been shown that pharmacological modulation of spinal microglial responses can effectively mitigate chronic pain. ${ }^{44}$ In the present study, microglial activation accompanying phenotype changes was observed in the ipsilateral TGs stained with anti-Ibal antisera following ION injury, indicating that activated microglial cells may contribute to the initiation and maintenance of neuropathic orofacial pain after trigeminal nerve injury.

NPY is widely distributed in the central and peripheral nervous systems. ${ }^{45}$ Both inhibitory and excitatory effects have been reported for NPY, depending on which receptor is involved. ${ }^{46,47}$ Our findings that NPY is low in the contralateral TGs, but significantly upregulated in the ipsilateral TGs after ION injury, are similar to NPY expression in DRG neurons after sciatic nerve injury. ${ }^{16,48-50}$ Our data are also in agreement with several previous reports, which indicate that NPY was upregulated in TGs following inferior alveolar nerve (IAN) injury. ${ }^{49,51,52} \mathrm{~A}$ very recent study using a mental nerve injury model in rats also showed an increased expression of NPY in ipsilateral TGs. ${ }^{53}$ Thus, upregulation of NPY in injured TG neurons indicates a role of NPY in persistent abnormal sensations.

GAL, a 29-amino acid peptide, appears to play a role in pain modulation. ${ }^{54} \mathrm{GAL}$ and its mRNA are found in TGs. After peripheral injury, no change, upregulation, or downregulation of GAL in TGs has been reported. ${ }^{16,55,56}$ Our data here are in agreement with previous reports that GAL is also expressed in mouse TGs. However, in this study, no significant change of GAL was found in injured TGs after ION injury, indicating that peripheral nerve injury has less influence on GAL synthesis in the TGs than in the DRGs. The quantitative differences in GAL expression from these studies may be related to variations in time periods, models, or species.

It has been established that CGRP and SP have excitatory effects on DRG and spinal neurons. ${ }^{57}$ Regarding regulation in the DRGs, peripheral nerve injury reduces the expression of CGRP and SP, while peripheral inflammation induced by complete Freund's adjuvant or carrageenan instead increases their expressions. ${ }^{58-60}$ Interestingly, in ferret TGs, the expression of CGRP and SP was either downregulated after IAN transection or showed no change after IAN ligation. ${ }^{13,16}$ Here, we report no significant changes of CGRP or SP in mouse TGs following partial ION injury. Our data suggest that these two neuropeptides may have less impact on ION injury-induced abnormal sensations in mice.

Recent studies indicate that purinergic signaling plays important roles in physiological and pathophysiological processes. ${ }^{61,62}$ Purinergic receptors are widely distributed in mammalian tissues, and these receptors are generally divided into three classes: $\mathrm{P} 1, \mathrm{P} 2 \mathrm{X}$, and $\mathrm{P} 2 \mathrm{Y}$ receptors. $\mathrm{P} 2 \mathrm{X}$ receptors are ionotropic and ATP sensitive and have been shown to be involved in nociceptive processing. ${ }^{63} \mathrm{P} 2 \mathrm{X} 3$ is mainly expressed in small-sized, nonpeptidergic neurons but also 
seen in some medium- and large-sized neurons in DRGs and can be regulated in different animal models. ${ }^{64-66}$ In rat TGs, transient expression of $\mathrm{P} 2 \mathrm{X} 3$ has been detected in response to trigeminal nerve injury. ${ }^{64,67}$ Although the proportion of P2X3-positive NPs in mouse TGs remains unchanged at 2 weeks postoperation in the present study, a role of $\mathrm{P} 2 \mathrm{X} 3$ in mediating the abnormal nociceptive process may still exist via enhanced sensitivity of $\mathrm{P} 2 \mathrm{X} 3$ receptors as suggested by a previous study. ${ }^{63}$

It is known that nNOS produces nitric oxide (NO) in the nervous system. ${ }^{68}$ As a neuronal neurotransmitter and/or neuromodulator, NO is involved in multiple biological processes, including modulation of pain. ${ }^{69-71}$ nNOS is regulated following the peripheral nerve injury in both DRGs and TGs, ${ }^{72,73}$ and nerve injury-induced hypersensitivity or allodynia can be attenuated by a pharmacological inhibition of nNOS. ${ }^{74-76}$ In the present study, we quantified the number of nNOS-positive NPs in TGs 2 weeks after ION transection. We did not find a significant difference in nNOS expression between the ipsilateral and contralateral TGs. In contrast to our findings, a significant upregulation of nNOS-IR neurons was seen in ipsilateral TGs 7 days after IAN injury, accompanied by significantly increased levels of two NO indicators, nitrate and nitrite. ${ }^{75}$ Interestingly, the same group also demonstrated that the levels of the two indicators in ipsilateral TGs went back to the control levels 14 days after injury, suggesting that a transient expression pattern of nNOS exists in injured TGs. Furthermore, the dramatic increase of nNOS in TGs 7 days, but not 14 days, after injury implies that NO may play a role at the early stage of neuropathic pain.

Phosphatidylinositol 3-kinase (PI3-K)/AKT signaling is believed to be important for promoting neuronal cell survival and axonal outgrowth. ${ }^{77}$ We have previously investigated the expression of pAKT in mouse DRGs and spinal cord following sciatic nerve axotomy or carrageenan-induced inflammation. ${ }^{5}$ In normal control animals, pAKT was found in both peptidergic and nonpeptidergic DRG neurons. After nerve injury, pAKT-IR neurons were seen in ipsilateral DRG neurons coexpressed with GAL but not NPY. In addition, we also found that the intensity of pAKT-LI in DRGs was increased in axotomized animals. To our knowledge, pAKT expression in TGs has been much less characterized. In this study, we reported that peripheral ION injury did not change the proportion of pAKT-positive NPs. However, even without quantification, an increased intensity of pAKT-LI was detected in the ipsilateral TGs. Our findings suggest that there is a PI3-K/AKT signaling pathway in trigeminal system.

\section{Conclusion}

Trigeminal nerve injury causes marked plasticity of biomarkers in TGs. Significant changes observed in injured TGs suggest that NPY and Iba1 may play crucial roles in the pathogenesis of orofacial neuropathic pain, in response to peripheral nerve injury.

\section{Acknowledgments}

This work was supported by the China Scholarship Council (CSC) award to Dr Chuang Lyu (HIT, 2013) and the Summer Course Supervision Foundation, Karolinska Institutet, Sweden. We especially thank Doctor Tomas Hökfelt and Doctor Kaj Fried for kindly providing all antibodies and materials used in this study, as well as their valuable advice.

\section{Author contributions}

RL, CL, GL, and T-JSS performed experiments, analyzed the data, and wrote the manuscript. XS, AR, and KM analyzed the data and wrote the manuscript. All authors contributed toward data analysis, drafting and critically revising the paper and agree to be accountable for all aspects of the work.

\section{Disclosure}

The authors report no conflicts of interest in this work.

\section{References}

1. Jeon HJ, Han SR, Park MK, Yang KY, Bae YC, Ahn DK. A novel trigeminal neuropathic pain model: compression of the trigeminal nerve root produces prolonged nociception in rats. Prog Neuropsychopharmacol Biol Psychiatry. 2012;38(2):149-158.

2. Gilron I, Watson CP, Cahill CM, Moulin DE. Neuropathic pain: a practical guide for the clinician. CMAJ. 2006;175(3):265-275.

3. Wang X, Liang H, Zhou C, Xu M, Xu L. Sensitization induces hypersensitivity in trigeminal nerve. Clin Exp Allergy. 2012;42(11): $1638-1642$.

4. Ma F, Zhang L, Lyons D, Westlund KN. Orofacial neuropathic pain mouse model induced by Trigeminal Inflammatory Compression (TIC) of the infraorbital nerve. Mol Brain. 2012;5:44.

5. Shi TJ, Huang P, Mulder J, Ceccatelli S, Hokfelt T. Expression of p-Akt in sensory neurons and spinal cord after peripheral nerve injury. Neurosignals. 2009;17(3):203-212.

6. Shi TJ, Hua XY, Lu X, et al. Sensory neuronal phenotype in galanin receptor 2 knockout mice: focus on dorsal root ganglion neurone development and pain behaviour. Eur J Neurosci. 2006;23(3):627-636.

7. Mulder H, Zhang Y, Danielsen N, Sundler F. Islet amyloid polypeptide and calcitonin gene-related peptide expression are down-regulated in dorsal root ganglia upon sciatic nerve transection. Brain Res Mol Brain Res. 1997;47(1-2):322-330.

8. Cunha TM, Souza GR, Domingues AC, et al. Stimulation of peripheral kappa opioid receptors inhibits inflammatory hyperalgesia via activation of the PI3Kgamma/AKT/nNOS/NO signaling pathway. Mol Pain. 2012;8:10

9. Wang Q, Zhu H, Zou K, et al. Sensitization of $\mathrm{P} 2 \times 3$ receptors by cystathionine beta-synthetase mediates persistent pain hypersensitivity in a rat model of lumbar disc herniation. Mol Pain. 2015;11:15.

10. Liu BN, Han BX, Liu F. Neuroprotective effect of pAkt and HIF-1 alpha on ischemia rats. Asian Pac J Trop Med. 2014;7(3):221-225. 
11. Saito A, Narasimhan P, Hayashi T, Okuno S, Ferrand-Drake M, Chan PH. Neuroprotective role of a proline-rich Akt substrate in apoptotic neuronal cell death after stroke: relationships with nerve growth factor. J Neurosci. 2004;24(7):1584-1593.

12. Navarro $X$, Vivo M, Valero-Cabre A. Neural plasticity after peripheral nerve injury and regeneration. Prog Neurobiol. 2007;82(4):163-201.

13. Elcock C, Boissonade FM, Robinson PP. Changes in neuropeptide expression in the trigeminal ganglion following inferior alveolar nerve section in the ferret. Neuroscience. 2001;102(3):655-667.

14. Hirose K, Iwakura N, Orita S, et al. Evaluation of behavior and neuropeptide markers of pain in a simple, sciatic nerve-pinch pain model in rats. Eur Spine J. 2010;19(10):1746-1752.

15. Zhang X, Xu ZO, Shi TJ, et al. Regulation of expression of galanin and galanin receptors in dorsal root ganglia and spinal cord after axotomy and inflammation. Ann N Y Acad Sci. 1998;863:402-413.

16. Elcock C, Boissonade FM, Robinson PP. Neuropeptide expression in the ferret trigeminal ganglion following ligation of the inferior alveolar nerve. Arch Oral Biol. 2001;46(8):729-743.

17. Zimmermann M. Pathobiology of neuropathic pain. Eur J Pharmacol. 2001;429(1-3):23-37.

18. Takeda M, Tsuboi Y, Kitagawa J, Nakagawa K, Iwata K, Matsumoto S. Potassium channels as a potential therapeutic target for trigeminal neuropathic and inflammatory pain. Mol Pain. 2011;7:5.

19. Scholz J, Woolf CJ. Can we conquer pain? Nat Neurosci. 2002;5(suppl): 1062-1067.

20. Costigan M, Scholz J, Woolf CJ. Neuropathic pain: a maladaptive response of the nervous system to damage. Annu Rev Neurosci. 2009;32:1-32.

21. Luo DS, Zhang T, Zuo CX, et al. An animal model for trigeminal neuralgia by compression of the trigeminal nerve root. Pain Physician. 2012;15(2):187-196.

22. Luiz AP, Schroeder SD, Rae GA, Calixto JB, Chichorro JG. Contribution and interaction of kinin receptors and dynorphin A in a model of trigeminal neuropathic pain in mice. Neuroscience. 2015;300: 189-200.

23. Henry MA, Fairchild DD, Patil MJ, et al. Effect of a novel, orally active matrix metalloproteinase- 2 and -9 inhibitor in spinal and trigeminal rat models of neuropathic pain. J Oral Facial Pain Headache. 2015;29(3):286-296.

24. Luiz AP, Kopach O, Santana-Varela S, Wood JN. The role of Nav1.9 channel in the development of neuropathic orofacial pain associated with trigeminal neuralgia. Mol Pain. 2015;11:72.

25. Vos BP, Strassman AM, Maciewicz RJ. Behavioral evidence of trigeminal neuropathic pain following chronic constriction injury to the rat's infraorbital nerve. J Neurosci. 1994;14(5 pt 1):2708-2723.

26. Idanpaan-Heikkila JJ, Guilbaud G. Pharmacological studies on a rat model of trigeminal neuropathic pain: baclofen, but not carbamazepine, morphine or tricyclic antidepressants, attenuates the allodynia-like behaviour. Pain. 1999;79(2-3):281-290.

27. Imamura $Y$, Kawamoto H, Nakanishi O. Characterization of heathyperalgesia in an experimental trigeminal neuropathy in rats. Exp Brain Res. 1997;116(1):97-103.

28. Bennett GJ, Xie YK. A peripheral mononeuropathy in rat that produces disorders of pain sensation like those seen in man. Pain. 1988;33(1): 87-107.

29. Stanic D, Paratcha G, Ledda F, Herzog H, Kopin AS, Hokfelt T. Peptidergic influences on proliferation, migration, and placement of neural progenitors in the adult mouse forebrain. Proc Natl Acad Sci U S A. 2008;105(9):3610-3615.

30. Theodorsson E, Rugarn O. Radioimmunoassay for rat galanin: immunochemical and chromatographic characterization of immunoreactivity in tissue extracts. Scand J Clin Lab Invest. 2000;60(5):411-418.

31. Shi TJ, Li J, Dahlstrom A, et al. Deletion of the neuropeptide Y Y1 receptor affects pain sensitivity, neuropeptide transport and expression, and dorsal root ganglion neuron numbers. Neuroscience. 2006;140(1): 293-304.
32. Lyu C, Mulder J, Barde S, et al. G protein-gated inwardly rectifying potassium channel subunits 1 and 2 are down-regulated in rat dorsal root ganglion neurons and spinal cord after peripheral axotomy. Mol Pain. 2015;11:44.

33. Su J, Gao T, Shi T, et al. Phenotypic changes in dorsal root ganglion and spinal cord in the collagen antibody-induced arthritis mouse model. J Comp Neurol. 2015;523(10):1505-1528.

34. Taves S, Berta T, Chen G, Ji RR. Microglia and spinal cord synaptic plasticity in persistent pain. Neural Plast. 2013;2013:753656.

35. Alvarez P, Brun A, Labertrandie A, et al. Antihyperalgesic effects of clomipramine and tramadol in a model of posttraumatic trigeminal neuropathic pain in mice. J Orofac Pain. 2011;25(4):354-363.

36. Pozza DH, Castro-Lopes JM, Neto FL, Avelino A. Spared nerve injury model to study orofacial pain. Indian J Med Res. 2016;143(3):297-302.

37. Kernisant M, Gear RW, Jasmin L, Vit JP, Ohara PT. Chronic constriction injury of the infraorbital nerve in the rat using modified syringe needle. J Neurosci Methods. 2008;172(1):43-47.

38. Deseure K, Hans G. Behavioral study of non-evoked orofacial pain following different types of infraorbital nerve injury in rats. Physiol Behav. 2015;138:292-296.

39. Tsujino H, Kondo E, Fukuoka T, et al. Activating transcription factor 3 (ATF3) induction by axotomy in sensory and motoneurons: a novel neuronal marker of nerve injury. Mol Cell Neurosci. 2000;15(2): 170-182.

40. Shortland PJ, Baytug B, Krzyzanowska A, McMahon SB, Priestley JV, Averill S. ATF3 expression in L4 dorsal root ganglion neurons after L5 spinal nerve transection. Eur J Neurosci. 2006;23(2):365-373.

41. Xu M, Aita M, Chavkin C. Partial infraorbital nerve ligation as a model of trigeminal nerve injury in the mouse: behavioral, neural, and glial reactions. J Pain. 2008;9(11):1036-1048.

42. Marchand F, Perretti M, McMahon SB. Role of the immune system in chronic pain. Nat Rev Neurosci. 2005;6(7):521-532.

43. Romero-Sandoval A, Chai N, Nutile-McMenemy N, Deleo JA. A comparison of spinal Ibal and GFAP expression in rodent models of acute and chronic pain. Brain Res. 2008;1219:116-126.

44. Jaken RJ, van Gorp S, Joosten EA, et al. Neuropathy-induced spinal GAP-43 expression is not a main player in the onset of mechanical pain hypersensitivity. J Neurotrauma. 2011;28(12):2463-2473.

45. Yalamuri SM, Brennan TJ, Spofford CM. Neuropeptide $\mathrm{Y}$ is analgesic in rats after plantar incision. Eur J Pharmacol. 2013;698(1-3): 206-212.

46. Molosh AI, Sajdyk TJ, Truitt WA, Zhu W, Oxford GS, Shekhar A. NPY Y1 receptors differentially modulate GABAA and NMDA receptors via divergent signal-transduction pathways to reduce excitability of amygdala neurons. Neuropsychopharmacology. 2013;38(7): $1352-1364$.

47. Gotzsche CR, Woldbye DP. The role of NPY in learning and memory. Neuropeptides. 2016;55:79-89.

48. Itotagawa $\mathrm{T}$, Yamanaka $\mathrm{H}$, Wakisaka $\mathrm{S}$, et al. Appearance of neuropeptide Y-like immunoreactive cells in the rat trigeminal ganglion following dental injuries. Arch Oral Biol. 1993;38(8):725-728.

49. Wakisaka S, Sasaki Y, Kurisu K. Temporal analysis of neuropeptide Y expression in the rat trigeminal ganglion following peripheral axotomy of the inferior alveolar nerve. Neurosci Lett. 1995;188(1):49-52.

50. Wakisaka S, Kajander KC, Bennett GJ. Effects of peripheral nerve injuries and tissue inflammation on the levels of neuropeptide Y-like immunoreactivity in rat primary afferent neurons. Brain Res. 1992;598(1-2):349-352.

51. Fristad I, Heyeraas KJ, Kvinnsland IH. Neuropeptide Y expression in the trigeminal ganglion and mandibular division of the trigeminal nerve after inferior alveolar nerve axotomy in young rats. Exp Neurol. 1996;142(2):276-286.

52. Khullar SM, Fristad I, Brodin P, Kvinnsland IH. Upregulation of growth associated protein 43 expression and neuronal co-expression with neuropeptide $\mathrm{Y}$ following inferior alveolar nerve axotomy in the rat. J Peripher Nerv Syst. 1998;3(2):79-90. 
53. Magnussen C, Hung SP, Ribeiro-da-Silva A. Novel expression pattern of neuropeptide $\mathrm{Y}$ immunoreactivity in the peripheral nervous system in a rat model of neuropathic pain. Mol Pain. 2015;11:31.

54. Tofighi R, Barde S, Palkovits M, et al. Galanin and its three receptors in human pituitary adenoma. Neuropeptides. 2012;46(5):195-201.

55. Zhang X, Ji RR, Arvidsson J, et al. Expression of peptides, nitric oxide synthase and NPY receptor in trigeminal and nodose ganglia after nerve lesions. Exp Brain Res. 1996;111(3):393-404.

56. Henken DB, Martin JR. The proportion of galanin-immunoreactive neurons in mouse trigeminal ganglia is transiently increased following corneal inoculation of herpes simplex virus type-1. Neurosci Lett. 1992;140(2):177-180.

57. Hokfelt T, Zhang X, Wiesenfeld-Hallin Z. Messenger plasticity in primary sensory neurons following axotomy and its functional implications. Trends Neurosci. 1994;17(1):22-30.

58. Hanesch U, Pfrommer U, Grubb BD, Heppelmann B, Schaible HG. The proportion of CGRP-immunoreactive and SP-mRNA containing dorsal root ganglion cells is increased by a unilateral inflammation of the ankle joint of the rat. Regul Pept. 1993;46(1-2):202-203.

59. Weihe E, Nohr D, Schafer MK, et al. Calcitonin gene related peptide gene expression in collagen-induced arthritis. Can J Physiol Pharmacol. 1995;73(7):1015-1019.

60. Calza L, Pozza M, Zanni M, Manzini CU, Manzini E, Hokfelt T. Peptide plasticity in primary sensory neurons and spinal cord during adjuvant-induced arthritis in the rat: an immunocytochemical and in situ hybridization study. Neuroscience. 1998;82(2):575-589.

61. Baroja-Mazo A, Barbera-Cremades M, Pelegrin P. The participation of plasma membrane hemichannels to purinergic signaling. Biochim Biophys Acta. 2013;1828(1):79-93.

62. Seiffert K, Ding W, Wagner JA, Granstein RD. ATPgammaS enhances the production of inflammatory mediators by a human dermal endothelial cell line via purinergic receptor signaling. J Invest Dermatol. 2006;126(5):1017-1027.

63. Chen M, Gu JG. A P2X receptor-mediated nociceptive afferent pathway to lamina I of the spinal cord. Mol Pain. 2005;1:4.

64. Tsuzuki K, Kondo E, Fukuoka T, et al. Differential regulation of P2X(3) mRNA expression by peripheral nerve injury in intact and injured neurons in the rat sensory ganglia. Pain. 2001;91(3):351-360.
65. Kage K, Niforatos W, Zhu CZ, Lynch KJ, Honore P, Jarvis MF. Alteration of dorsal root ganglion $\mathrm{P} 2 \times 3$ receptor expression and function following spinal nerve ligation in the rat. Exp Brain Res. 2002;147(4):511-519.

66. Xiang Z, Xiong Y, Yan N, et al. Functional up-regulation of $\mathrm{P} 2 \times 3$ receptors in the chronically compressed dorsal root ganglion. Pain. 2008;140(1):23-34.

67. Eriksson J, Bongenhielm U, Kidd E, Matthews B, Fried K. Distribution of $\mathrm{P} 2 \times 3$ receptors in the rat trigeminal ganglion after inferior alveolar nerve injury. Neurosci Lett. 1998;254(1):37-40.

68. Karacay B, Bonthius DJ. The neuronal nitric oxide synthase (nNOS) gene and neuroprotection against alcohol toxicity. Cell Mol Neurobiol. 2015;35(4):449-461.

69. Cury Y, Picolo G, Gutierrez VP, Ferreira SH. Pain and analgesia: the dual effect of nitric oxide in the nociceptive system. Nitric Oxide. 2011;25(3):243-254.

70. Freire MA, Guimaraes JS, Leal WG, Pereira A. Pain modulation by nitric oxide in the spinal cord. Front Neurosci. 2009;3(2):175-181.

71. Hancock CM, Riegger-Krugh C. Modulation of pain in osteoarthritis: the role of nitric oxide. Clin J Pain. 2008;24(4):353-365.

72. Kim KH, Kim JI, Han JA, Choe MA, Ahn JH. Upregulation of neuronal nitric oxide synthase in the periphery promotes pain hypersensitivity after peripheral nerve injury. Neuroscience. 2011;190:367-378.

73. Davies SL, Loescher AR, Clayton NM, Bountra C, Robinson PP, Boissonade FM. nNOS expression following inferior alveolar nerve injury in the ferret. Brain Res. 2004;1027(1-2):11-17.

74. Tesser-Viscaino SA, Denadai-Souza A, Teixeira SA, et al. Putative antinociceptive action of nitric oxide in the caudal part of the spinal trigeminal nucleus during chronic carrageenan-induced arthritis in the rat temporomandibular joint. Brain Res. 2009;1302:85-96.

75. Sugiyama T, Shinoda M, Watase T, et al. Nitric oxide signaling contributes to ectopic orofacial neuropathic pain. J Dent Res. 2013;92(12): 1113-1117.

76. Guan Y, Yaster M, Raja SN, Tao YX. Genetic knockout and pharmacologic inhibition of neuronal nitric oxide synthase attenuate nerve injuryinduced mechanical hypersensitivity in mice. Mol Pain. 2007;3:29.

77. Askvig JM, Watt JA. The MAPK and PI3K pathways mediate CNTFinduced neuronal survival and process outgrowth in hypothalamic organotypic cultures. J Cell Commun Signal. 2015;9(3):217-231.
Journal of Pain Research

\section{Publish your work in this journal}

The Journal of Pain Research is an international, peer reviewed, open access, online journal that welcomes laboratory and clinical findings in the fields of pain research and the prevention and management of pain. Original research, reviews, symposium reports, hypothesis formation and commentaries are all considered for publication

\section{Dovepress}

The manuscript management system is completely online and includes a very quick and fair peer-review system, which is all easy to use. Visit http://www.dovepress.com/testimonials.php to read real quotes from published authors. 